\title{
Empirical Evidence of Associations and Similarities between the National Equity Markets Indexes and Crude Oil Prices in the International Market
}

\author{
Andre Assis de Salles ${ }^{*}{ }^{(0)}$, Maria Eduarda Silva² (i) Paulo Teles $^{2}$ (1) \\ ${ }^{1}$ Polytechnic School, Federal University of Rio de Janeiro, Rio de Janeiro, Brazil \\ ${ }^{2}$ FEP, School of Economics and Management, University of Porto, Porto, Portugal \\ Email: *as@ufrj.br
}

How to cite this paper: Salles, A. A., Silva, M. E., \& Teles, P. (2022). Empirical Evidence of Associations and Similarities between the National Equity Markets Indexes and Crude Oil Prices in the International Market Open Journal of Business and Management, 10, 155-174.

https://doi.org/10.4236/ojbm.2022.101010

Received: November 2, 2021

Accepted: January 4, 2022

Published: January 7, 2022

Copyright $\odot 2022$ by author(s) and Scientific Research Publishing Inc. This work is licensed under the Creative Commons Attribution International License (CC BY 4.0).

http://creativecommons.org/licenses/by/4.0/

\begin{abstract}
The stock market is a major component of the financial sector of any economy and it is particularly affected by crude oil price. Moreover, the financialization of the oil market in the last three decades increased its association with the financial markets. The main purpose of this paper is to uncover similarities among the economy of selected countries based on the association between their national stock markets and crude oil price. This is achieved by time series clustering of the conditional correlations between the national stock market index returns and crude oil price returns estimated from bivariate GARCH models. The clusters do not lead to a clear classification concerning the countries' stage of development, emerging and developed, or the geographical region which can be explained by crude oil market financialization.
\end{abstract}

\section{Keywords}

Crude Oil Prices, Stock Markets, Multivariate GARCH Models, Time Series Clustering

\section{Introduction}

The way expectations of economic and financial variables are generated is crucial for economic agents and particularly in financial markets. Among those variables, stock market performance is especially important, being an economic leading indicator. Furthermore, this market provides resources for investment and production financing. Consequently, knowledge of the stock market per- 
formance relevant factors is necessary to determine the behavior of the expectations in such market and, more generally, in global and domestic economies. The crude oil benchmark price change in the international market is one of those factors. In fact, oil is directly or indirectly present in every productive activity and consequently crude oil price movements are relevant for the expectations concerning productive activities' returns, equity returns and the stock market. Thus, the crude oil market is related to financial markets and, in particular, to the stock market. Furthermore, oil is a cost for importing countries and a revenue for producers, making it important for economic development. Crude oil price changes have a direct impact on domestic and foreign trade, on developed and emerging countries' financial markets, on investment and on productive activity financing. Growing economic and market integration that has occurred together with globalization has brought a stronger association between different types of markets, particularly the oil and stock markets. It is also important to mention the increasing creation and trading of indexed financial instruments or derivatives and of spot and futures commodity markets in the past decades, especially in the oil market, leading to the financialization of those markets and strengthening their association with the financial markets. Moreover, investors and portfolio managers can diversify their investments, intensifying the use of commodity markets and their derivatives.

In the last decades, studies and researches have focused on inference concerning the data generating process of the crude oil or stock prices returns, their volatility and associations, to improve stock price expectations. A large part of those researchers has studied the relationship between crude oil and equity prices.

The main purpose of this paper is to uncover similarities among the economy of selected countries based on the association between their national stock markets and crude oil price. To this end, we use a two-stage approach. First, we estimate the time-varying conditional correlation between the national stock market index returns and crude oil price returns using bivariate GARCH models. Second, we search for similarities among these conditional correlations using appropriate time series clustering methods. The clusters thus obtained provide useful information for investors and portfolio managers concerning the optimal allocation of financial resources in the international market. Hence, this work contributes to related literature presenting the contagion between crude oil prices and national markets equity indices through the association and the similarities of these associations. Furthermore, it must highlight that the relevance of the selected sample period contributes to the study of the effects of the most recent major financial crisis. Since the sample comprises the period close to the most significant financial crisis, the subprime crisis or 2008 crisis, that was affected severely affected the national economies and to the world economy.

The rest of the paper is organized as follows. Section 2 provides a brief overview of the literature review, while Section 3 presents methodological issues regarding bivariate GARCH models and time series clustering. Section 4 describes 
the data used in the study. The results obtained are analyzed in Section 5, and Section 6 finalizes the paper.

\section{Literature Review}

Among studies and researches have been developed to evaluate the relationship between crude oil prices and equity market practiced prices, some works were selected for a brief review of the related literature presented in the following paragraphs.

Chen, Roll, \& Ross (1986) tested the hypothesis of influence of crude oil price on stock prices in the US stock market and, unlike the results of other studies, they did not find evidence to support that hypothesis. Ferson \& Harvey (1995) showed evidence of the influence of crude oil prices on the stock market of 18 countries with different impacts. In order to test whether oil price shocks cause any reaction on the Canadian, Japanese, UK and US stock markets and based on quarterly data, Jones \& Kaul (1996) showed the existence of a relationship between crude oil prices and the returns of those markets. Fall \& Brailsford (1999) analyzed the influence of crude oil prices on sectors of the Australian stock market, in order to explain the returns of those sectors through an augmented market model or a two-factor market model derived from the diagonal model introduced in the finance literature by Sharpe (1963). They rejected the hypothesis of influence of crude oil price in only 4 out of the 24 sectors studied. Based on a vector autoregressive model (VAR), Sadorsky (1999) confirmed that the crude oil price return and volatility are important for economic activity. Sadorsky (1999) suggested that crude oil price movements are relevant to explaining economic activity but that those movements have little influence on oil prices. Papapetrou (2001) investigated the interaction of crude oil prices with stock prices and some macroeconomic variables in Greece, showing that oil price changes have direct influence on economic activity. Sadorsky (2003) showed that, among several macroeconomic factors, crude oil prices have a significant impact on the equity capital volatility in the technology sector of the US stock market. Hammoudeh \& Aleisa (2004) obtained a close empirical relationship between crude oil and equity prices in some Gulf Cooperation Council member states. Based on daily data, Hammoudeh, Didooglu, \& Aleisa (2004) made a large study concerning the effects of crude oil prices on the oil industry in the USA with cointegration tests and GARCH models and suggested that the oil industry market, the crude oil market and the stock market offer opportunities for portfolio diversification. The results by Maghyereh (2004) showed that crude oil price shocks were not significant for the index returns of equities traded in developed countries. Basher \& Sadorsky (2006) studied the relationship between crude oil and stock prices returns based on an asset pricing model. Nandha \& Faff (2008) analyzed the stock indices of 35 industrial sectors and their results showed a negative relationship between crude oil prices and stock market re- 
turns with the exceptions of the mining and oil and gas sectors. Tansuchat, Chang, \& McAleer (2010) studied conditional correlations and volatility spillovers between crude oil returns and stock market indices using multivariate GARCH models. The results indicate that, in fact, the crude oil and financial markets are dependent. Also, the results of Huang, Hu, Cheng, \& Chen (2011) showed a relationship between oil prices and stock market indices. Using cointegration and causality tests and VAR models, Yazdan, Ehsan, \& Hossein (2012) showed the existence of a causal relationship between oil prices and Iranian economic growth. Bhunia (2012) also tested oil prices and three Bombay stock exchange indices for cointegration and causality. The results indicate that stock market prices are not causal for oil prices but there is no evidence to reject cointegration between oil prices and the selected stock indices. Recently, Ratti \& Hasan (2013) studied the effect of oil price change and volatility on the returns and volatility of certain sectors of the Australian stock market, using a GARCH models approach. The results indicate that, for the sectors of materials and energy, the relationship is positive but it is negative for the remaining sectors considered in the study. Tang \& Xiong (2012) results suggest that the positive correlation between daily returns of oil and stock markets is due not only to supply and demand shocks but also to the financialization of the oil market. Further, D'Ecclesia, Magrini, Montalbano, \& Triulzi (2014) argue that the financialization of commodity markets leads to a new class of financial assets to improve investment.

Section 3 below presents the methodological approach used to achieve the objectives of this work and make contributions to the literature related to the topic discussed.

\section{Methodology Approach}

This section describes the statistical methodologies used. First, bivariate GARCH models are fitted to Brent crude oil price returns and national stock market index returns leading to implied conditional correlation series. Then, time series clustering techniques are used to cluster the conditional correlation series.

\subsection{Multivariate Garch Models}

Consider a stochastic vector process $\left\{Y_{t}\right\}$ of dimension $k \times 1$ and let $I_{t-1}$ denote the $\sigma$-field generated by the past information up to time $t-1$. Then we write

$$
\begin{aligned}
& Y_{t}=\mu_{t}(\theta)+e_{t} \\
& e_{t}=H_{t}^{\frac{1}{2}}(\theta) Z_{t}
\end{aligned}
$$

where $\theta$ is a vector of parameters, $\mu_{t}(\theta)$ is conditional mean vector, $e_{t}$ is a $k \times 1$ vector of serially uncorrelated random variates with $\mathrm{E}\left(e_{t}\right)=0$ and covariance matrix $H_{t}(\theta)$, which is a $k \times k$ positive definite matrix, $\left\{Z_{t}\right\}$ is a $k \times 1$ random vector with $\mathrm{E}\left(Z_{t}\right)=0$ and $\operatorname{Var}\left(Z_{t}\right)=I_{k}$, the identity matrix of order 
$k$. It is clear from the above that $\operatorname{Var}\left(Y_{t} \mid I_{t-1}\right)=H_{t}$, where for simplicity of notation $\theta$ is omitted. There are several specifications for $H_{t}$ (Bauwens, Laurent, \& Rombouts, 2006) but in this work we consider the diagonal $\operatorname{VECH}(1,1)$ (D-VECH) proposed by Bollerslev, Engle, \& Wooldridge (1988) and defined by as follows:

$$
\operatorname{Vech}\left(H_{t}\right)=C+A \operatorname{Vech}\left(e_{t-1} e_{t-1}^{\prime}\right)+B \operatorname{Vech}\left(H_{t-1}\right)
$$

where $\operatorname{Vech}(\cdot)$ denotes the operator that stacks the lower triangular portion of a $k \times k$ matrix as a $k(k+1) / 2 \times 1$ vector. $A$ and $B$ are diagonal parameter matrices of order $k(k+1) / 2$ and $C$ is a $k(k+1) / 2 \times 1$ parameter vector. It is easy to see that the conditional covariance satisfies the following equation $h_{i j t}=c_{i j}+\alpha_{i j} e_{i t-1} e_{j t-1}+\beta_{i j} h_{i j t}, i, j=1, \cdots, k$ where $\omega_{i j}, \alpha_{i j}$ and $\beta_{i j}$ are $3 k(k+1) / 2$ parameters. Thus, each element $h_{i j t}$ of $H_{t}$ depends only on its own lagged value and on the previous value of $e_{t}$. The diagonal VECH model can be written as follows:

$$
H_{t}=C^{o}+A^{o} \odot e_{t-1} e_{t-1}^{\prime}+B^{o} \odot H_{t-1}
$$

where $\odot$ is the Hadamard product and $A^{o}, B^{o}$ and $C^{o}$ are symmetric $k \times$ $k$ matrices. If the parameters in the matrices are allowed to vary without any restrictions, i.e. parameterized as indefinite matrices, then there is no guarantee that $H_{t}$ will be positive definite. There are, however, several parameterizations for these matrices that, together with an unconditional positive definite variance matrix $H_{0}$, ensure the positive-definiteness of $H_{t}$ (Ding \& Engle, 2001). The matrix diagonal model parametrizes the matrices $C^{o}, A^{o}$ and $B^{o}$ as $C^{o}=C C^{\prime}$, $A^{o}=A A^{\prime}$ and $B^{o}=B B^{\prime}$ so that the positive semi-definiteness is guaranteed in estimation without imposing any further restrictions. The vector-diagonal or rank one model considers the matrices $A^{o}$ and $B^{o}$ to be of rank one and therefore $A^{o}=a a^{\prime}$ and $B^{o}=b b^{\prime}$, where $a$ and $b$ are $k \times 1$ vectors. The scalar diagonal or two-parameter model considers a very strong restriction in which the matrices $A^{o}$ and $B^{o}$ are scalars, $A^{o}=\alpha$ and $B^{o}=\beta$. Additionally, the following restrictions may be imposed on the constant matrix $C^{\circ}$, given as

$$
C^{o}=H_{0}\left(1,1_{t}^{\prime}-A-B\right)
$$

where $1_{k}$ is a $k \times 1$ vector of ones, leading to the so called variance targeting model. Given a bivariate time series $Y_{1}, \cdots, Y_{T}$, estimation of the parameters $\theta$ of the VECH models is accomplished by maximum likelihood (ML). This requires the construction of a likelihood function and consequently an assumption on the distribution for the iid innovation process $Z_{t}$. The most commonly employed distribution is the multivariate normal in which case the likelihood function is

$$
L(\theta)=-\frac{1}{2} \sum_{t=1}^{T} \log \left|H_{t}\right|-\frac{1}{2} \sum_{t=1}^{T}\left(Y_{t}-\mu_{t}\right)^{\prime} H_{t}^{-1}\left(Y_{t}-\mu_{t}\right)
$$

It is, however, well known that most daily or weekly financial data present high kurtosis, rejecting the normality assumption. However, Bollerslev \& Wooldridge 
(1992) show that a consistent estimator may still be obtained from maximizing (5), yielding a quasi-maximum likelihood estimator provided the conditional mean and the conditional variance are specified correctly. A natural alternative to the multivariate Gaussian distribution is the Student distribution, as in Harvey, Ruiz, \& Sentana (1992) and Fiorentini, Sentana, \& Shepard (2003), the approach used.

\subsection{Time Series Clustering}

The fundamental issue in time series classification and clustering is the choice of a metric. There are several metrics for time series proposed in the literature which can be broadly classified as model based or feature based, in the time domain or in the frequency domain (Caiado, Crato, \& Peña, 2006). We consider a feature based approach and an approach in the time domain. The first method, proposed by Wang, Smith, \& Hyndman (2006), is characteristic-based because it clusters global features extracted from each $\mathrm{k}$ time series using a hierarchical clustering algorithm. Seven characteristics of the correlation coefficient time series are considered, namely: trend, serial correlation, skewness, kurtosis and non-linearity, self-similarity (Hurst coefficient) and chaos (Lyapunov coefficient). These measures are normalized to the interval $[0,1]$ to indicate the degree of presence of the feature. A measure near zero for a certain time series indicates near absence of the feature, while a measure near 1 indicates a strong presence. The set of feature measures extracted from each the time series forms the input vector for the hierarchical clustering algorithms directly without the need for further data pre-processing. The hierarchical clustering algorithm is a well-known clustering method which starts by considering the interval $[0,1]$ to indicate the degree of presence of the feature. A measure near zero for a certain time series indicates near absence of the feature, while a measure near one indicates a strong presence. The set of feature measures extracted from each the time series forms the input vector for the hierarchical clustering algorithms directly without the need for further data pre-processing. The hierarchical clustering algorithm is a well-known clustering method which starts by considering each time series as a separate cluster, forming $k$ clusters or groups. Subsequently, the closest two groups are linked to form $k-1$ clusters. This process continues until the last stage in which all the time series are in the same cluster. We use Ward's algorithm which is a minimum-variance algorithm (Jain, Murthy, \& Flynn, 1999) implemented in (R Core Team, 2015).

The other approach for time series clustering considered here is based on defining the Mahalanobis distance between sample autocorrelation coefficient vectors as the similarity measure between two time series $X, Y$ as proposed by Caiado, Crato \& Peña (2006):

$$
d_{A C F M}(X, Y)=\sqrt{\left(\hat{\rho}_{X}-\hat{\rho}_{Y}\right)^{\mathrm{T}} \Omega\left(\hat{\rho}_{X}-\hat{\rho}_{Y}\right)}
$$

where $\hat{\rho}_{i}, i=X, Y$ represents the vector of sample autocorrelation coefficients, 
$\hat{\rho}_{i}=\left(\hat{\rho}_{i, 1}, \cdots, \hat{\rho}_{i, m}\right)$ for some $m$ such as $\hat{\rho}_{i, j} \approx 0$ for $j>m$, and $\Omega$ is the inverse covariance matrix of the sample autocorrelations which is given by Bartlett's formula (Brockwell \& Davis, 1991). Other time series similarity measures were tried in the data set under study and the results were almost coincident. Thus a distance matrix is defined and Ward's hierarchical clustering algorithm is used on that matrix.

In order to facilitate the interpretation of the clustering results, we use two well-known techniques: multidimensional scaling and the hierarchical clustering tree or dendrogram (Johnson \& Wichern, 2007). The multidimensional scaling, also often referred to as principal coordinate analysis, creates a configuration of $\mathrm{k}$ points in a lower-dimensional map, usually of dimension two or three. Letting $D$ be the observed $k \times k$ dissimilarity matrix and applying multidimensional scaling to $D$ returns a $k \times s$ configuration matrix $T$, where the rows of $T$ are the coordinate values of the $k$ points in the s-dimensional representation for some $s$ $<k$. The dimensionality that accurately reproduces $D$ is given by the largest $s$ eigenvalues of $T T^{\prime}$. A scatter plot of the coordinate values provides a visual representation of the original distances. The dendrogram is a tree diagram which illustrates the arrangement of the clusters produced by hierarchical clustering. The height of each node in the plot is proportional to the value of the intergroup dissimilarity between its two daughters (the bottom nodes representing individual observations are all plotted at zero height).

\section{Sample Used and Data Description}

The data are the weekly close quotations of the representative aggregate stock market indices from 48 different countries and of the Brent crude oil price negotiated in the London Market. The stock market index primary data were compiled from DataStream and the Brent crude oil price from EIA (US Energy Information Administration). All data were collected in current US dollars. The sample spans from January 2nd, 2004 to October 3rd, 2014. Return time series $R_{t}$ are constructed from the weekly quotes $\left(I_{t}\right)$ as $R_{t}=\ln I_{t}-\ln I_{t-1}$, a total of 562 observations.

Table 1 and Table 2 present a statistical summary of the return time series as well as the economic country classification in nine groups, according to Kotkatvuori-Örnberg, Nikkinen \& Äijö (2013) and the Morgan Stanley Capital International (MSCI) (nd), as follows: developed Asia Pacific (dAP), developed Europe (dE), G7, developed Middle East (dME), emerging Middle East (eME), emerging Africa (eA), emerging Asia Pacific (eAP), emerging Europe (eE), emerging Latin America (eLA). The Brent crude oil price and the World Equity Index statistical summary are shown in Table 3, which presents the results of the Jarque-Bera test (JB) and the Augmented Dickey-Fuller test (ADF) for these time series. The descriptive statistics for the return time series show return means ranging between -0.0014 and 0.0018 . Among the stock market indices, the lowest mean of returns occurs in Greece followed by Italy and Portugal while 
A. A. Salles et al.

Table 1. Statistical summary of Latin American market index-developed countries.

\begin{tabular}{|c|c|c|c|c|c|c|c|c|c|}
\hline Index & ID & Mean & Min & $\operatorname{Max}$ & Std D. & Skew & Kurt & $J B$ test & $A D F$ test \\
\hline \multicolumn{10}{|l|}{ Asia Pacific (dAP) } \\
\hline Australia & $\mathrm{HK}$ & 0.0011 & -0.3552 & 0.1324 & 0.0375 & -2.0599 & 19.033 & 6416.7 & -5.10 \\
\hline Hong Kong (China) & $\mathrm{HK}$ & 0.0011 & -0.1766 & 0.1190 & 0.0310 & -0.3308 & 6.293 & 264.2 & -23.95 \\
\hline New Zealand & $\mathrm{NZ}$ & 0.0006 & -0.2370 & 0.1027 & 0.0288 & -1.6749 & 13.688 & 2937.8 & -4.73 \\
\hline Singapore & SG & 0.0016 & -0.1963 & 0.1855 & 0.0301 & -0.6033 & 11.626 & 1776.4 & -14.36 \\
\hline \multicolumn{10}{|l|}{ Europe (dE) } \\
\hline Austria & $\mathrm{AT}$ & 0.0006 & -0.3634 & 0.1865 & 0.0437 & -1.5749 & 13.685 & 2905.6 & -4.85 \\
\hline Belgium & $\mathrm{BE}$ & 0.0006 & -0.2832 & 0.1025 & 0.0342 & -1.6205 & 12.869 & 2526.6 & -4.51 \\
\hline Denmark & DK & 0.0020 & -0.2459 & 0.1322 & 0.0348 & -1.5207 & 11.397 & 1867.6 & -4.83 \\
\hline Finland & FI & 0.0004 & -0.2018 & 0.1181 & 0.0374 & -0.8892 & 6.325 & 333.0 & -4.45 \\
\hline Greece & GR & -0.0014 & -0.2576 & 0.1712 & 0.0472 & -0.6346 & 5.502 & 184.3 & -14.59 \\
\hline Ireland & IE & 0.0000 & -0.3511 & 0.1403 & 0.0394 & -1.8756 & 16.258 & 4445.3 & -3.85 \\
\hline Netherlands & NL & 0.0003 & -0.3096 & 0.1390 & 0.0352 & -1.4825 & 15.110 & 3639.8 & -4.69 \\
\hline Norway & NO & 0.0016 & -0.2887 & 0.2075 & 0.0450 & -1.0261 & 9.605 & 1120.1 & -24.24 \\
\hline Portugal & $\mathrm{PT}$ & -0.0004 & -0.2278 & 0.1023 & 0.0341 & -1.3025 & 8.707 & 921.5 & -23.06 \\
\hline Spain & ES & 0.0005 & -0.2604 & 0.1253 & 0.0393 & -1.1032 & 8.612 & 851.4 & -4.93 \\
\hline Sweden & SE & 0.0013 & -0.2385 & 0.1615 & 0.0389 & -0.7841 & 8.150 & 678.6 & -4.79 \\
\hline Switzerland & $\mathrm{CH}$ & 0.0013 & -0.2433 & 0.1310 & 0.0278 & -1.5452 & 16.510 & 4497.2 & -5.07 \\
\hline \multicolumn{10}{|l|}{ G7 } \\
\hline Canada & $\mathrm{CA}$ & 0.0013 & -0.2663 & 0.1637 & 0.0340 & -1.4282 & 13.540 & 2792.3 & -6.99 \\
\hline France & FR & 0.0003 & -0.2726 & 0.1386 & 0.0359 & -1.1956 & 10.628 & 1496.4 & -4.99 \\
\hline Germany & $\mathrm{DE}$ & 0.0015 & -0.2656 & 0.1451 & 0.0366 & -1.0995 & 10.189 & 1323.3 & -5.09 \\
\hline Japan & $\mathrm{JP}$ & 0.0006 & -0.2198 & 0.0701 & 0.0275 & -1.1213 & 10.184 & 1326.2 & -24.62 \\
\hline Italy & IT & -0.0005 & -0.2657 & 0.1306 & 0.0399 & -1.1955 & 8.578 & 862.4 & -4.95 \\
\hline United Kingdom & UK & 0.0005 & -0.2782 & 0.1628 & 0.0314 & -1.5077 & 16.893 & 4732.5 & -4.32 \\
\hline United States & US & 0.0010 & -0.2008 & 0.1136 & 0.0247 & -0.9916 & 12.840 & 2358.9 & -5.29 \\
\hline \multicolumn{10}{|l|}{ Middle East (dME) } \\
\hline Israel & IL & 0.0019 & -0.1741 & 0.1483 & 0.0330 & -0.7670 & 7.480 & 525.0 & -24.73 \\
\hline
\end{tabular}

Table 2. Statistical summary of Latin American market index-emerging countries.

\begin{tabular}{cccccccccc}
\hline Index & ID & Mean & Min & Max & Std D. & Skew & Kurt & JB test & ADF test \\
\hline $\begin{array}{c}\text { Africa (eA) } \\
\text { South Africa }\end{array}$ & ZA & 0.0019 & -0.1741 & 0.1483 & 0.0330 & -0.7670 & 7.4796 & 525.01 & -24.73 \\
\hline $\begin{array}{c}\text { Asia Pacific (eAP) } \\
\text { Chinese mainland }\end{array}$ & CN & 0.0013 & -0.1462 & 0.1369 & 0.0346 & 0.0366 & 4.9260 & 86.99 & -3.44 \\
India & IN & 0.0018 & -0.1965 & 0.2162 & 0.0397 & -0.4591 & 6.7278 & 345.16 & -5.62 \\
\hline
\end{tabular}


Continued

\begin{tabular}{|c|c|c|c|c|c|c|c|c|c|}
\hline Indonesia & ID & 0.0028 & -0.2774 & 0.1706 & 0.0398 & -1.0880 & 9.2788 & 1034.04 & -8.61 \\
\hline Malaysia & MY & 0.0018 & -0.1008 & 0.0745 & 0.0219 & -0.6612 & 5.6747 & 208.48 & -14.86 \\
\hline Philippine & PH & 0.0033 & -0.2136 & 0.1275 & 0.0335 & -0.8923 & 7.5999 & 570.05 & -24.77 \\
\hline Pakistan & PK & 0.0024 & -0.2095 & 0.1082 & 0.0337 & -1.4331 & 8.9622 & 1024.80 & -9.60 \\
\hline South Korea & $\mathrm{KR}$ & 0.0015 & -0.2703 & 0.2963 & 0.0423 & -0.3551 & 11.2518 & 1606.31 & -5.37 \\
\hline Taiwan (China) & TW & 0.0008 & -0.1235 & 0.0918 & 0.0311 & -0.6283 & 4.4039 & 83.13 & -15.78 \\
\hline Thailand & $\mathrm{TH}$ & 0.0016 & -0.2888 & 0.1297 & 0.0358 & -1.0384 & 10.8013 & 1526.13 & -5.10 \\
\hline \multicolumn{10}{|l|}{ Europe (eE) } \\
\hline Czech Republic & $\mathrm{CZ}$ & 0.0010 & -0.3278 & 0.1894 & 0.0419 & -1.2107 & 12.1165 & 2083.47 & -5.17 \\
\hline Hungary & $\mathrm{HU}$ & 0.0001 & -0.3744 & 0.2041 & 0.0494 & -1.0438 & 10.6380 & 1468.15 & -22.56 \\
\hline Poland & PL & 0.0010 & -0.2634 & 0.2400 & 0.0465 & -0.7758 & 7.7023 & 574.16 & -22.95 \\
\hline Russia & RU & 0.0012 & -0.2373 & 0.3419 & 0.0501 & -0.3445 & 9.5654 & 1020.47 & -5.20 \\
\hline Turkey & TR & 0.0016 & -0.2852 & 0.2460 & 0.0535 & -0.4009 & 5.8960 & 211.45 & -15.23 \\
\hline \multicolumn{10}{|c|}{ Latin America (eLA) } \\
\hline Argentina & $\mathrm{AR}$ & 0.0023 & -0.3303 & 0.1713 & 0.0470 & -1.1823 & 10.2172 & 1350.64 & -15.51 \\
\hline Brazil & BR & 0.0017 & -0.3306 & 0.2562 & 0.0513 & -0.6684 & 9.4698 & 1022.01 & -15.87 \\
\hline Chile & CL & 0.0017 & -0.3326 & 0.1712 & 0.0348 & -1.8496 & 19.7196 & 6866.49 & -6.81 \\
\hline Colombia & $\mathrm{CO}$ & 0.0037 & -0.2730 & 0.1242 & 0.0391 & -1.4408 & 10.8516 & 1638.04 & -10.73 \\
\hline Mexico & MX & 0.0026 & -0.3020 & 0.2391 & 0.0405 & -0.6989 & 13.4179 & 2587.22 & -5.22 \\
\hline Peru & $\mathrm{PE}$ & 0.0033 & -0.4161 & 0.1744 & 0.0461 & -1.3281 & 17.3111 & 4961.10 & -6.17 \\
\hline \multicolumn{10}{|l|}{ Middle East (eME) } \\
\hline Arab Emirates & UE & 0.0019 & -0.1849 & 0.1708 & 0.0323 & -0.3220 & 8.4064 & 694.17 & -6.56 \\
\hline Egypt & EG & 0.0035 & -0.2606 & 0.1466 & 0.0440 & -1.0015 & 8.1372 & 711.94 & -6.87 \\
\hline Qatar & QA & 0.0022 & -0.2290 & 0.1555 & 0.0384 & -0.6383 & 8.7632 & 815.93 & -22.93 \\
\hline
\end{tabular}

Table 3. Statistical summary of return time series-world index and Brent Crude Oil.

\begin{tabular}{cccccccccc}
\hline Other Time Series & Mean & Min & Max & Std D. & Skew & Kurt & $\begin{array}{c}\text { JB } \\
\text { test }\end{array}$ & $\begin{array}{c}\text { ADF } \\
\text { test }\end{array}$ \\
\hline $\begin{array}{c}\text { World Equity Index } \\
\text { Brent Crude Oil }\end{array}$ & 0.0020 & -0.2534 & 0.2414 & 0.0456 & -0.5211 & 6.460 & 305.8 & -11.95 \\
\hline
\end{tabular}

the largest occurs in Colombia followed by Egypt and Indonesia. While for emerging markets, particularly the BRICS, the means of returns are close to each other, ranging from 0.0012 to 0.0018 , the same is not true for the developed markets, particularly the G7 countries.

Note that, except for the Chinese market, the median is always greater than the mean indicating a negative skewness. The standard deviation of the returns ranges from 0.0258 to 0.0535 , indicating high volatility. Among the stock market 
indices, the highest volatility occurs in Turkey followed by Brazil and Russia whereas the lowest occurs in the US followed by Japan and Switzerland. It must be emphasized that emerging markets present the highest volatility whereas the developed markets show the lowest.

Except for China, all the skewness coefficients are negative and all the kurtosis coefficients indicate leptokurtic series. Thus, all the time series show a departure from the normal distribution, confirmed by the results of the Jarque-Bera test (JB) in Table 1. Moreover, the results of the Augmented Dickey-Fuller test (ADF) in Table 1 indicate stationarity. It is worth mentioning that all the p-value obtained in the JB and ADF tests is close to zero. Finally, the Ljung-Box test (LB) shows no serial correlation except for New Zealand.

\section{Empirical Results Obtained}

In order to investigate the relationship between the Brent crude oil price returns and the selected national stock market index returns, bivariate Diagonal-VECH models are fitted considering a constant mean, $\mu_{t}=\mu$ and innovations distributed as Student-t with one degree of freedom, $Z_{i, t} \sim t(1), i=1,2$. For each bivariate model, the parametrization of the matrices $C, A$ and $B$ is chosen according to the Akaike (AIC) and the Schwartz (BIC) criteria, yet ensuring the semi-positive definiteness of matrix $H_{t}$. Since there is no statistically significant bivariate model for Chinese mainland (CN), Hong Kong (China) (HK), Malaysia (MY), Pakistan (PK), Taiwan (China) (TW) and United Arab Emirates (AE), the stock market index returns of these six countries are discarded.

The conditional correlations between Brent crude oil price returns and national stock market index returns implied by the estimated models for the remaining 42 countries are represented in Figure 1 and Figure 2. The plots show that the dynamic correlations between Brent price returns and national stock market returns present two main features: either trend or high variability with spikes. Furthermore, the features of the correlation coefficient time series differ even for countries that belong to a same economic group. For instance, among the G7 countries, Germany (DE) and United Kingdom (UK) series exhibit similar behavior with local trends in the mean, while the United States (US), Japan (JP), Italy (IT) and France (FR) are characterized by high variability and some spikes. Moreover, Canada (CA) exhibits a different behavior from all the other countries in the group with high positive correlation over time.

Similar remarks may be made for the other groups, as shown in Figure 1 and Figure 2. It is thus appropriate to cluster the correlation coefficient time series for further analysis. To this purpose, the feature based approach described in Section 2 is used first. The multidimensional scaling of the corresponding dissimilarity matrix between the features extracted from the correlation time series results in a set of eigenvalues which indicate that a 2-dimensional representation of the distance matrix is appropriate. In fact, the first two eigenvalues account $95.01 \%$ of the sum of all the eigenvalues and the first one accounts for $89.13 \%$. 


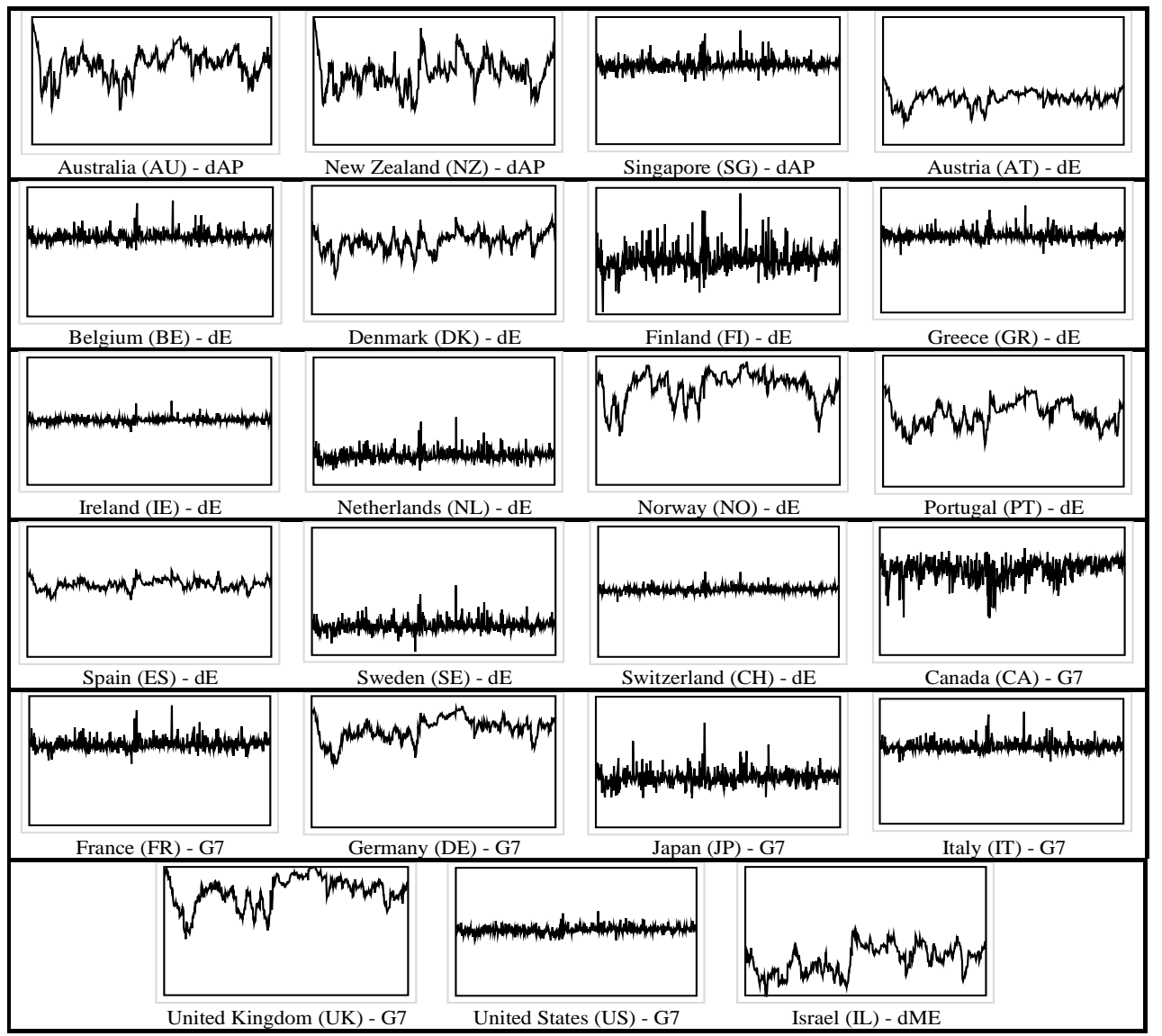

Figure 1. Equity index and crude oil returns correlation series plots-developed countries.

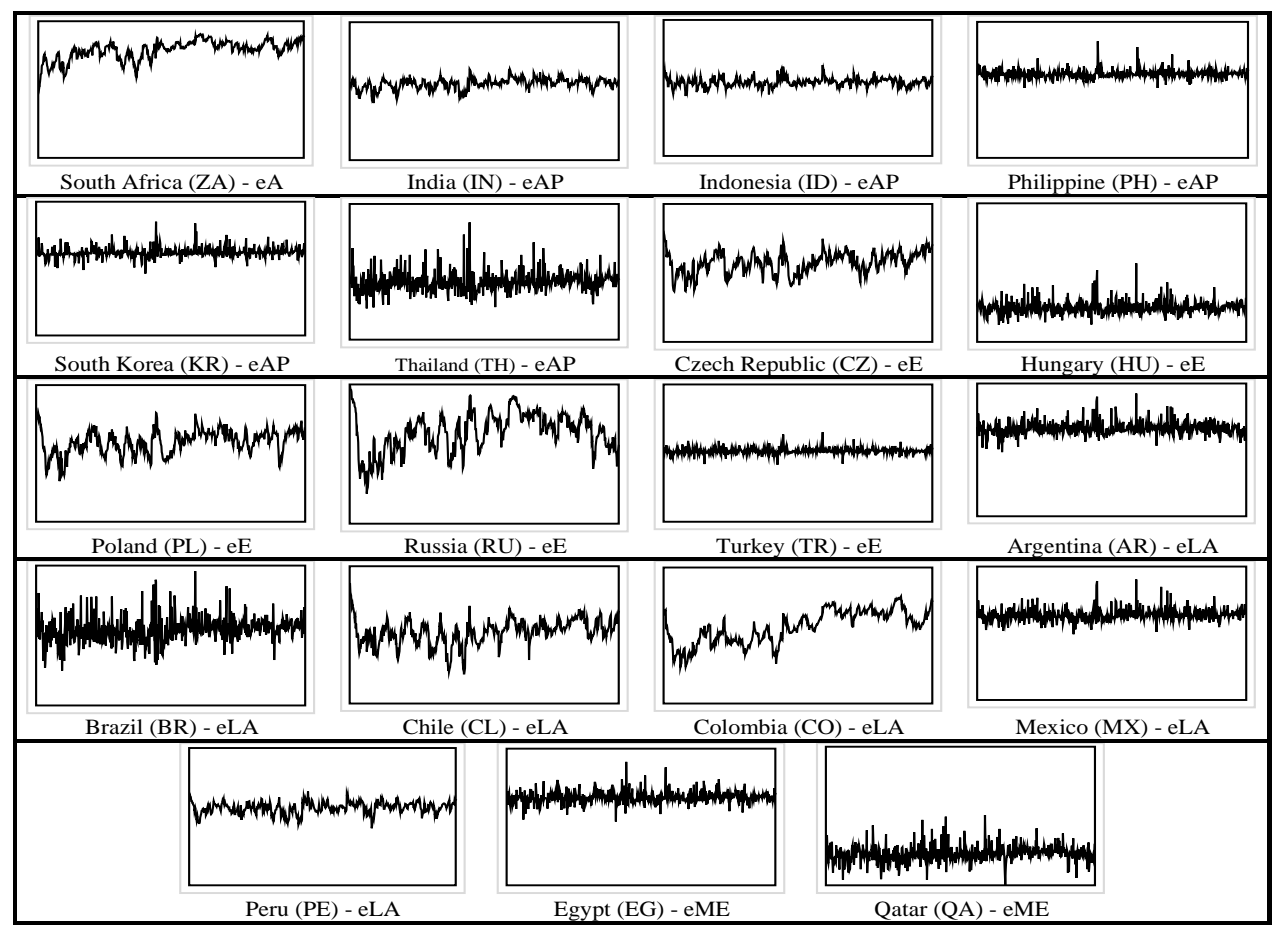

Figure 2. Equity index and crude oil returns correlation series plots-emerging countries. 
Accordingly, representing the countries in the scaling map of Figure 3, three main clusters are easily identified: a group with negative first coordinate $D_{I}=$ \{Australia (AU), Austria (AT), Chile (CL), Colombia (CO), Czech Republic (CZ), Germany (DE), Denmark (DK), Spain (ES), Israel (IL), India (IN), Norway (NO), New Zealand (NZ), Peru (PE), Poland (PL), Portugal (PT), Russia (RU), the United Kingdom (UK), South Africa (ZA)\}; another one, with positive first coordinate $D_{2}=\{$ Argentina (AR), Belgium (BE), Brazil (BR), Canada (CA), Switzerland (CH), Egypt (EG), Finland (FI), France (FR), Greece (GR), Hungary (HU), Ireland (IE), Italy (IT), Japan (JP), South Korea (KR), Mexico (MX), the Netherlands (NL), the Philippines (PH), Qatar (QA), Sweden (SE), Singapore (SG), Thailand (TH), Turkey (TR), the United States (US) $\}$; and a country $D_{3}=$ \{Indonesia (ID)\}, with negative but close to zero first coordinate, which is almost equidistant of the other two groups. The first group, with negative first coordinate, shows smaller intra-group distances than the second group, with positive first dimension. In fact, the second group can be divided in four sub-groups stand out from the latter: $D_{2.1}=\{$ Canada (CA) $\} ; D_{2.2}=\{$ Brazil (BR), Qatar (QA) $\}$; $D_{2.3}=\{$ Argentina (AR), Switzerland (CH), Finland (FI), Egypt (EG), South Korea (KR), Thailand (TH), Turkey (TR), the United States (US) $\}$; and $D_{2.4}=$ \{Greece (GR), Hungary (HU), Mexico (MX), Sweden (SE), Japan (JP), Singapore (SG), France (FR), Ireland (IE)\}. In the scaling map shown in Figure 3, clusters D1, D2 and D3 are indicated by a circle on a dotted line, a rectangular figure and a circle on a solid line, respectively.

The dendrogram resulting from the hierarchical clustering displayed in Figure 4 indicates four reasonable clusters: $C_{H 1}=\{$ Austria (AT), Colombia (CO),

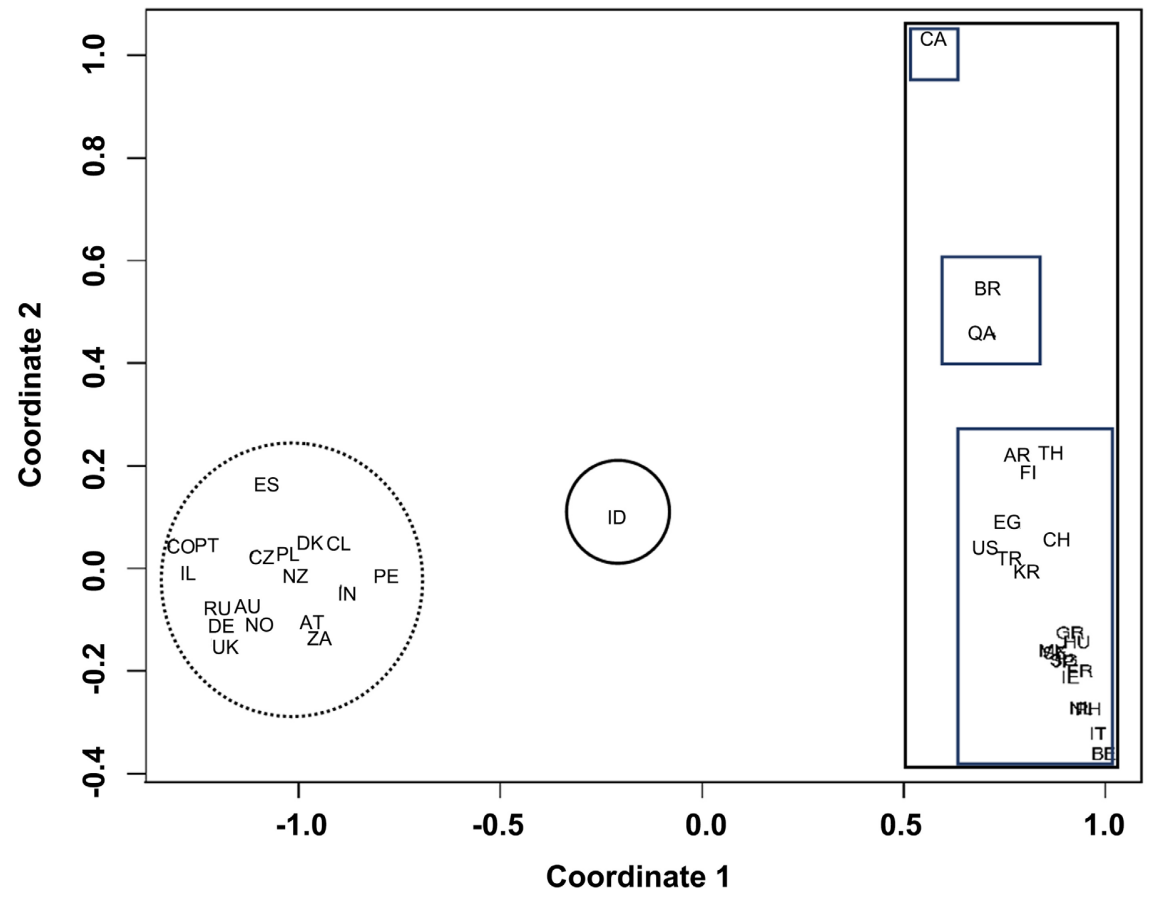

Figure 3. Multidimensional scaling for feature based distance. 


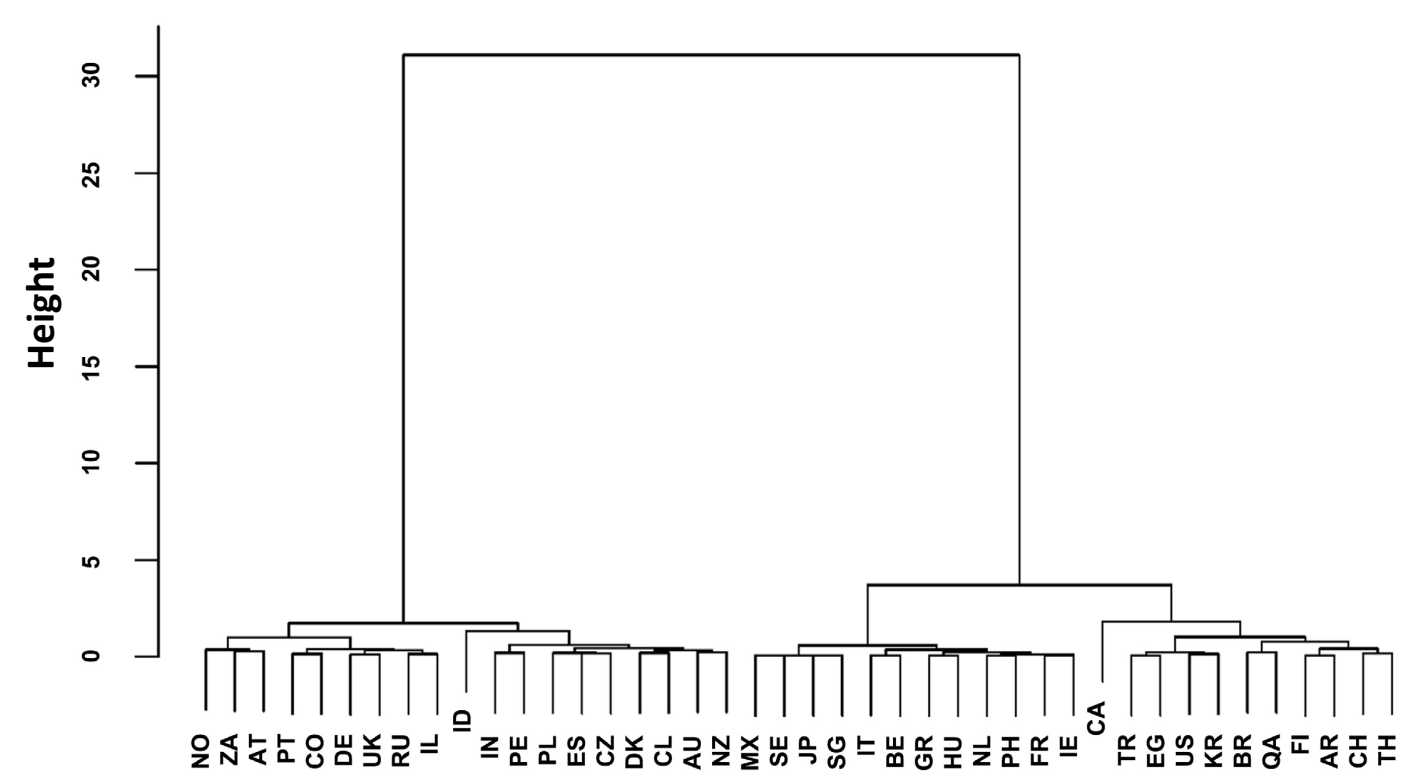

Figure 4. Dendrogram for feature based clustering.

Germany (DE), Israel (IL), Norway (NO), Portugal (PT), Russia (RU), the United Kingdom (UK), South Africa (ZA) $\} ; C_{H 2}=\{$ Australia (AU), Chile (CL), Czech Republic (CZ), Denmark (DK), Spain (ES), Indonesia (ID), India (IN), New Zealand (NZ), Peru (PE), Poland (PL) $\} ; C_{H 3}=\{$ Belgium (BE), France (FR), Greece (GR), Hungary (HU), Ireland (IE), Italy (IT), Japan (JP), Mexico (MX), the Netherlands (NL), the Philippines (PH), Sweden (SE), Singapore (SG)\}; and $C_{H 4}=\{$ Argentina (AR), Brazil (BR), Canada (CA), Switzerland (CH), Egypt (EG), Finland (FI), South Korea (KR), Qatar (QA), Thailand (TH), Turkey (TR), the United States (US)\}. Note that $C_{H 1} \cup C_{H 2}=D_{1} \cup D_{3}$ and $C_{H 3} \cup C_{H 4}=D_{2}$. Thus both representations convey the same results. Using the Mahalanobis distance between sample autocorrelation coefficient vectors for clustering leads to the following three clusters: $C_{M 1}=C_{H 1} ; C_{M 2}=C_{H 2}$, with the exception of Australia (AU); and $C_{M 3}=C_{H 3} \cup C_{H 4}$. Since both approaches lead to similar results, only those yielded by the feature based clustering will be further analyzed.

Table 4 describes the mean and standard deviation of feature values for each cluster. Recall that the values of the features represent the degree of the presence of the feature, with values near one indicating the strong presence of the feature and values near zero its almost absence. Globally, cluster $C_{H 1}$ in Figure 5 is similar to cluster $C_{H 2}$ in Figure 6, as can be inferred from the dendrogram presents in Figure 4 . These clusters are characterized by predominantly positive correlations, the presence of an overall increasing trend over time with local levels, leading to high values of the autocorrelation and of the Hurst coefficient. The autocorrelation values remain high even after removing the trend. The correlation coefficient time series in these clusters do not present either skewness or kurtosis. On the contrary, as present in Figure 7 and Figure 8, clusters $C_{H 3}$ and $C_{H 4}$ are similar. The correlation series exhibit lower values, do not exhibit trend, 
Table 4. Summary of features measures for each cluster.

\begin{tabular}{ccccc}
\hline Coefficient & $\begin{array}{c}\text { Cluster } \\
C_{H 1}\end{array}$ & $\begin{array}{c}\text { Cluster } \\
C_{H 2}\end{array}$ & $\begin{array}{c}\text { Cluster } \\
C_{H 3}\end{array}$ & $\begin{array}{c}\text { Cluster } \\
C_{H 4}\end{array}$ \\
\hline & Mean (Std D.) & Mean (Std D.) & Mean (Std D.) & Mean (Std D.) \\
\hline Trend & $0.609(0.086)$ & $0.100(0.752)$ & $0.885(0.350)$ & $0.442(0.508)$ \\
Autocorrelation & $0.987(0.010)$ & $0.156(0.856)$ & $1.443(0.243)$ & $0.847(0.433)$ \\
Non-Linear & $0.035(0.029)$ & $0.243(0.866)$ & $1.811(0.153)$ & $1.188(0.321)$ \\
Skewness & $0.167(0.012)$ & $0.498(0.797)$ & $1.106(0.361)$ & $1.372(0.253)$ \\
Kurtosis & $0.160(0.018)$ & $0.584(0.712)$ & $0.731(0.603)$ & $1.196(0.321)$ \\
Hurst & $0.999(0.000)$ & $0.526(0.786)$ & $1.217(0.309)$ & $2.050(0.072)$ \\
Lyapunov & $0.982(0.003)$ & $0.806(0.643)$ & $0.995(0.468)$ & $1.817(0.074)$ \\
\hline
\end{tabular}

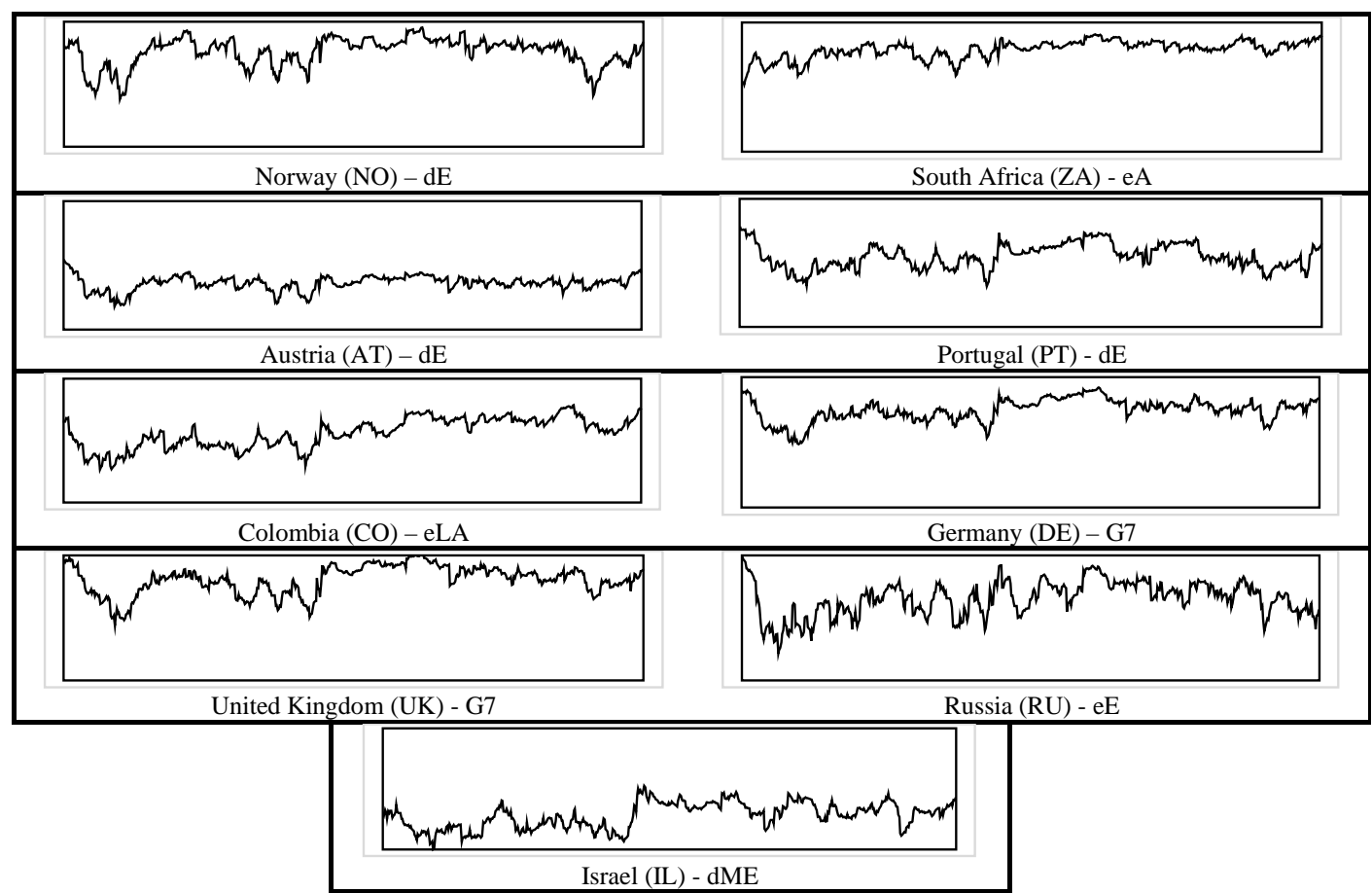

Figure 5. Equity index and crude oil returns correlation series plots-cluster $C_{H 1}$.

are serially uncorrelated but show high kurtosis. However, $C_{H 4}$ exhibits the highest degree of non-linearity among the four groups. Most interesting is the fact that the Lyapunov coefficient is high for all clusters indicating lack of short-term forecast ability of the correlation coefficient between the Brent crude oil price returns and national stock market index returns.

Group $C_{H 1}$ gathers mostly countries classified as developed, such as Israel (IL), or developed and European, namely Austria (AT), Germany (DE), Norway (NO), Portugal (PT), Russia (RU) and the United Kingdom (UK). Among the nine countries in this cluster, only Colombia (CO) and South Africa (ZA) are emerging countries. Cluster $C_{H 2}$ joins seven countries, out of the ten countries, that 


Indonesia (ID) - eAP

Figure 6. Equity index and crude oil returns correlation series plots-cluster $C_{H 2}$.

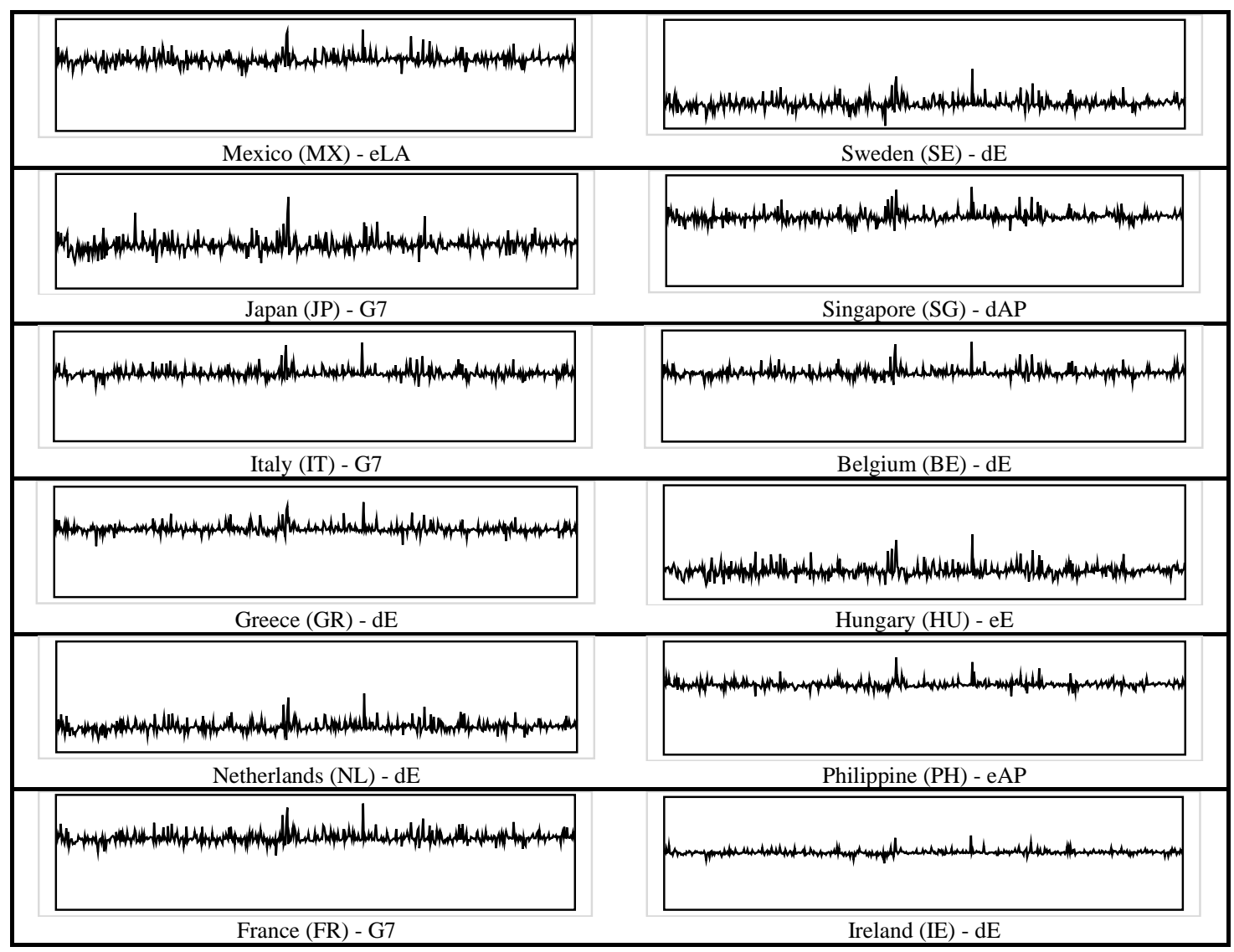

Figure 7. Equity index between crude oil returns correlation series plots-cluster $C_{H 3}$. 


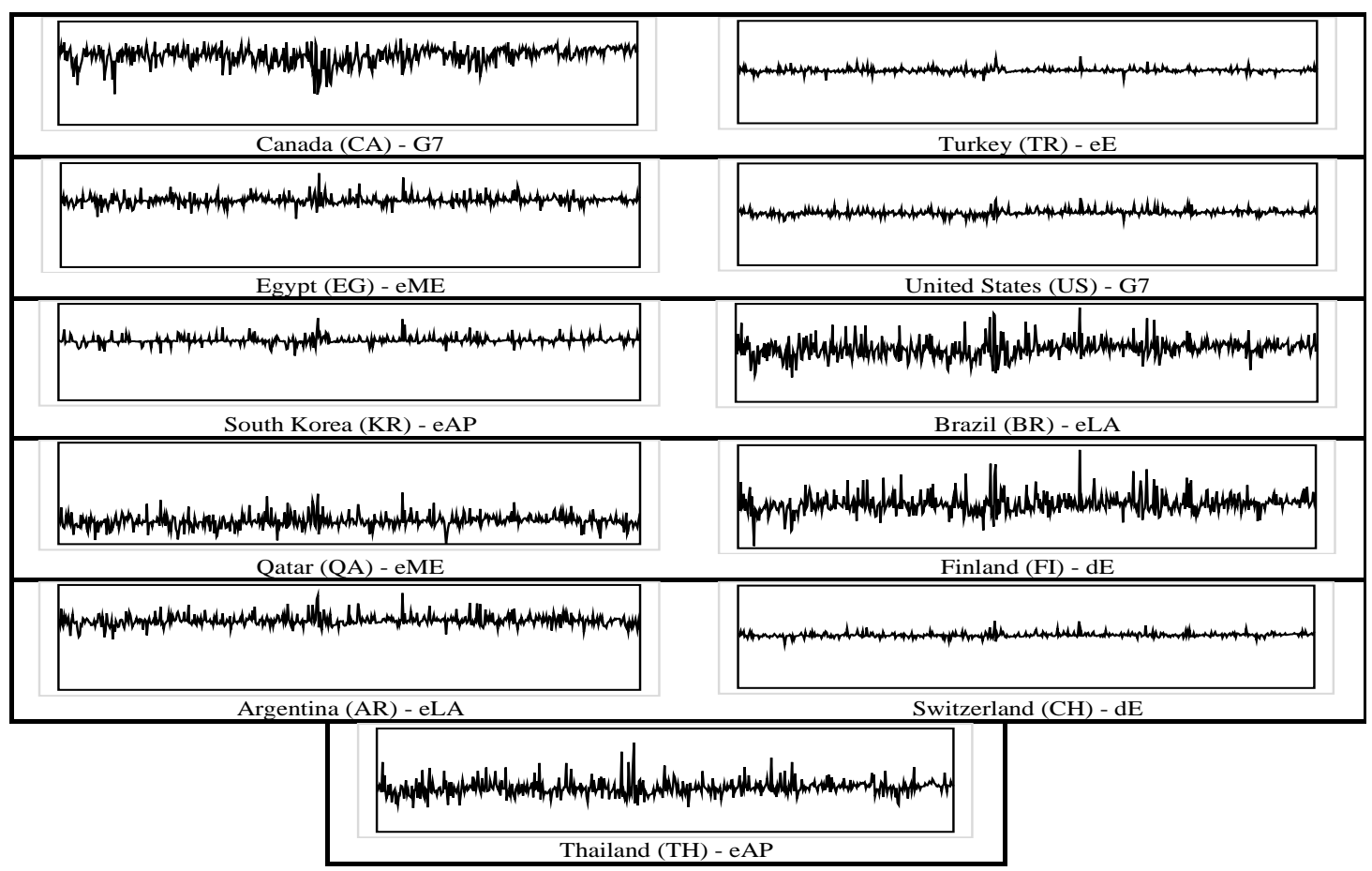

Figure 8. Equity index between crude oil returns correlation series plots-cluster $C_{H 4}$.

can be classified as emerging countries such as Chile (CL), Czech Republic (CZ), Indonesia (ID), India (IN), Peru (PE) and Poland (PL). The exceptions, or developed countries, in this cluster are Australia (AU), Denmark (DK), New Zealand (NZ) and Spain (ES). Among the twelve countries grouped in the $C_{H 3}$ cluster, nine can be classified as developed countries namely: Belgium (BE), France (FR), Greece (GR), Ireland (IE), Italy (IT), Japan (JP), the Netherlands (NL), Sweden (SE) and Singapore (SG). The remaining three countries, Mexico (MX), the Philippines $(\mathrm{PH})$ and Hungary $(\mathrm{HU})$ are emerging in Latin America, Asia and Europe respectively. Among the eleven countries of cluster $C_{H 4}$ only four can be classified as developed: Canada (CA), Switzerland (CH), United States (US) and Finland (FI). All the other countries in $C_{H 4}$ are classified as emerging economies.

Table 5 and Table 6 present the time series statistical summary of correlations coefficient grouped in $C_{H 1}, C_{H 2}, C_{H 3}$ and $C_{H 4}$ clusters. These statistical summaries allow observing the time series of the estimated correlation coefficients between the equity index returns of each country and the returns of crude oil prices in the international market similarities in a more detailed or precise form.

Thus, this work shows that the correlation between Brent crude oil price returns and national stock market index returns changes over time and that Brent crude oil price volatility is reflected in the stock market through this correlation. However, it is impossible to classify an economy as developed or emerging based on these time varying correlations. 
Table 5. Statistical summary of correlation time series-cluster $C_{H 1}$ and cluster $C_{H Z}$.

\begin{tabular}{cccccccccc}
\hline Cluster & \multicolumn{7}{c}{ Cluster } \\
$C_{H 1}$ & Mean & Std D. & Min & Max & $C_{H 2}$ & Mean & Std D. & Min & Max \\
\hline NO & 0.507 & 0.139 & 0.054 & 0.743 & ID & 0.168 & 0.123 & -0.243 & 0.676 \\
ZA & 0.377 & 0.138 & -0.162 & 0.612 & IN & 0.219 & 0.152 & -0.348 & 0.647 \\
AT & 0.323 & 0.112 & -0.045 & 0.670 & PE & 0.254 & 0.162 & -0.339 & 0.733 \\
PT & 0.262 & 0.114 & -0.018 & 0.532 & PL & 0.300 & 0.104 & -0.044 & 0.592 \\
CO & 0.274 & 0.142 & -0.082 & 0.543 & ES & 0.221 & 0.149 & -0.248 & 0.686 \\
DE & 0.292 & 0.173 & -0.228 & 0.640 & CZ & 0.289 & 0.092 & 0.040 & 0.560 \\
UK & 0.411 & 0.230 & -0.321 & 0.836 & DK & 0.281 & 0.088 & -0.040 & 0.509 \\
RU & 0.385 & 0.168 & -0.141 & 0.788 & CL & 0.224 & 0.109 & -0.139 & 0.645 \\
IL & 0.158 & 0.214 & -0.401 & 0.648 & AU & 0.353 & 0.133 & -0.077 & 0.752 \\
- & - & - & - & - & NZ & 0.270 & 0.144 & -0.077 & 0.784 \\
\hline
\end{tabular}

Table 6. Statistical summary of correlation time series-cluster $C_{H 3}$ and cluster $\boldsymbol{C}_{\boldsymbol{H} 4}$.

\begin{tabular}{cccccccccc}
\hline Cluster & \multicolumn{7}{c}{ Cluster } \\
$C_{H 3}$ & Mean & Std D. & Min & Max & $C_{H 4}$ & Mean & Std D. & Min & Max \\
\hline MX & 0.075 & 0.091 & -0.214 & 0.609 & CA & 0.402 & 0.098 & -0.051 & 0.605 \\
SE & 0.059 & 0.091 & -0.351 & 0.693 & TR & 0.057 & 0.083 & -0.345 & 0.610 \\
JP & 0.056 & 0.068 & -0.135 & 0.561 & EG & 0.085 & 0.085 & -0.268 & 0.608 \\
SG & 0.049 & 0.086 & -0.220 & 0.589 & US & 0.067 & 0.106 & -0.271 & 0.641 \\
IT & 0.036 & 0.079 & -0.213 & 0.595 & KR & 0.040 & 0.075 & -0.275 & 0.503 \\
BE & 0.037 & 0.075 & -0.176 & 0.594 & BR & 0.250 & 0.109 & -0.101 & 0.753 \\
GR & 0.029 & 0.073 & -0.278 & 0.515 & QA & 0.053 & 0.121 & -0.400 & 0.615 \\
HU & 0.096 & 0.094 & -0.154 & 0.735 & FI & 0.115 & 0.110 & -0.376 & 0.748 \\
NL & 0.061 & 0.086 & -0.175 & 0.662 & AR & 0.122 & 0.099 & -0.235 & 0.650 \\
PH & 0.036 & 0.059 & -0.171 & 0.519 & CH & 0.064 & 0.082 & -0.311 & 0.613 \\
FR & 0.053 & 0.086 & -0.250 & 0.652 & TH & 0.111 & 0.087 & -0.122 & 0.637 \\
IE & 0.033 & 0.075 & -0.347 & 0.631 & - & - & - & - & - \\
\hline
\end{tabular}

\section{Final Comments}

Energy price changes and, in particular, crude oil prices have a direct influence on economic activity. Determining this influence is valuable for national economic policymakers and all participants of national and global capital markets. The primary purpose of this paper was to analyze the dynamic correlation between Brent crude oil market returns and the domestic capital market returns.

To that purpose, bivariate GARCH models were first fitted to Brent crude oil price returns and national stock market index returns, leading to the estimation of implied dynamical correlations. Then, the correlation time series were clustered using two different, albeit related, time series distances. The clusters ob- 
tained by the two methodologies were essentially the same. They did not provide well defined clustering solutions concerning the country capital market rankings, the stage of development and the geographical region. Recent decades' greater integration of national capital markets may have contributed to the exceptions shown in the correlation time series clustering. It should be noted that those exceptions can also be caused by the financialization of the crude oil market, with its increasing indexed financial instruments or derivatives and their use in portfolio diversification.

It is worth mentioning that for six of the selected markets, namely Chinese mainland, Hong Kong (China), Malaysia, Pakistan, Taiwan (China) and United Arab Emirates (UAE), it was impossible to estimate a statistically significant bivariate GARCH model. This difficulty can be explained by the characteristics concerning the crude oil market supply and demand shocks and the dissociation of these markets from the global financial markets.

Further studies on this topic should be carried out using other samples and methodological approaches to gather more information to improve resource allocation in the international market.

\section{Conflicts of Interest}

The authors declare no conflicts of interest regarding the publication of this paper.

\section{References}

Basher, S., \& Sadorsky, P. (2006). Oil Price Risk and Emerging Stock Markets. Global Finance Journal, 17, 224-251. https://doi.org/10.1016/j.gfj.2006.04.001

Bauwens, L., Laurent, S., \& Rombouts, J. (2006). Multivariate GARCH Models: A Survey. Journal of Applied Econometrics, 71, 79-109. https://doi.org/10.1002/jae.842

Bhunia, A. (2012). Association between Crude Price and Stock Indices: Empirical Evidence from Bombay Stock Exchange. Journal of Economics and Sustainable Development, 3, 25-34.

http://citeseerx.ist.psu.edu/viewdoc/download?doi=10.1.1.916.8247\&rep=rep1\&type=pdf

Bollerslev, T., \& Wooldridge, J. M. (1992). Quasi-Maximum Likelihood Estimation and Inference in Dynamical Models with Time Varying Covariances. Economic Reviews, 11, 143-172. https://doi.org/10.1080/07474939208800229

Bollerslev, T., Engle, R. D., \& Wooldridge, J. M. (1988). A Capital Asset Pricing Model with Time Varying Covariances. Journal of Political Economy, 96, 116-131. https://doi.org/10.1086/261527

Brockwell, P. J., \& Davis, R. A. (1991). Time Series: Theory and Methods (2nd ed.). Springer. https://doi.org/10.1007/978-1-4419-0320-4

Caiado, J., Crato, N., \& Peña, D. (2006). A Periodogram-Based Metric for Time Series Classification. Computational Statistics and Data Analysis, 50, 2668-2684.

https://doi.org/10.1016/j.csda.2005.04.012

Chen, N., Roll, R., \& Ross, S. (1986). Economic Forces and the Stock Market. Journal of Business, 59, 383-403. https://doi.org/10.1086/296344

D’Ecclesia, R., Magrini, E., Montalbano, P., \& Triulzi, U. (2014). Understanding Recent 
Oil Price Dynamics: A Novel Empirical Approach. Energy Economics, 46, S11-S17. https://doi.org/10.1016/j.eneco.2014.10.005

Ding, Z., \& Engle, R. (2001). Large Scale Conditional Covariance Matrix Modeling, Estimation and Testing. NYU Working Paper No. S-DRP-01-07.

https://ssrn.com/abstract $=1296437$

Fall, R., \& Brailsford, T. (1999). Oil Price Risk and the Australian Stock Market. Journal of Energy Finance and Development, 4, 69-87. https://doi.org/10.1016/S1085-7443(99)00005-8

Ferson, W., \& Harvey, C. (1995). Predictability and Time-Varying Risk in World Equity Markets. Research in Finance, 13, 25-88.

https://faculty.fuqua.duke.edu/ charvey/Teaching/CDROM BA453 2003/Other_Harv ey Papers/P31 Predictability and time.pdf

Fiorentini, G., Sentana, E., \& Shepard, N. (2003). Maximum Likelihood Estimation and Inference in Multivariate Conditionally Heteroskedastic Dynamic Regression Models with Student T Innovations. Journal of Business and Economic Statistics, 21, 532-546. https://www.cemfi.es/ sentana/es/student.pdf https://doi.org/10.1198/073500103288619232

Hammoudeh, S., \& Aleisa, E. (2004). Dynamic Relationship among GCC Stock Markets and NYMEX Oil Futures. Contemporary Economic Policy, Western Economic Association International, 2, 250-269. https://doi.org/10.1093/cep/byh018

Hammoudeh, S., Didooglu, S., \& Aleisa, E. (2004). Relationships among U.S. Oil Prices and Oil Industry Equity Prices. International Review of Economics \& Finance, 13, 427-453. https://doi.org/10.1016/S1059-0560(03)00011-X

Harvey, A., Ruiz, E., \& Sentana, E. (1992). Unobservable Component Time Series Models with ARCH Disturbances. Journal of Econometrics, 52, 129-158.

https://doi.org/10.1016/0304-4076(92)90068-3

Huang, A., Hu, W., Cheng, C., \& Chen, C. (2011). Relationship between Crude Oil Prices and Stock Prices of Alternative Energy Companies with Recent Evidence. Economic Bulletin, 31, 2434-2443.

http://www.accessecon.com/Pubs/EB/2011/Volume31/EB-11-V31-I3-P218.pdf

Jain, A. K., Murthy, M. N., \& Flynn, P. J. (1999). Data Clustering: A Review. ACM Computing Surveys, 31, 265-323. https://doi.org/10.1145/331499.331504

Johnson, R., \& Wichern, D. (2007). Applied Multivariate Statistical Analysis (6th ed.). Prentice-Hall. https://doi.org/10.1002/0471667196.ess6094

Jones, C., \& Kaul, G. (1996). Oil and Stock Markets. Journal of Finance, 51, 463-491. https://doi.org/10.1111/j.1540-6261.1996.tb02691.x

Kotkatvuori-Örnberg, J., Nikkinen, J., \& Äijö, J. (2013). Stock Market Correlations during the Financial Crisis of 2008-2009: Evidence from 50 Equity Markets. International Review of Financial Analysis, 28, 70-78. https://doi.org/10.1016/j.irfa.2013.01.009

Maghyereh, A. (2004). Oil Price Shocks and Emerging Stock Markets: A Generalized VAR Approach. International Journal of Applied Econometrics and Quantitative Studies, 1, 27-40. https://www.usc.es/economet/reviews/ijaeqs122.pdf

Nandha, M., \& Faff, R. (2008). Does Oil Move Equity Prices? A Global View. Energy Economics, 30, 986-997. https://doi.org/10.1016/j.eneco.2007.09.003

Papapetrou, E. (2001). Oil Price Shocks, Stock Markets, Economic Activity and Employment in Greece. Energy Economics, 23, 511-532. https://doi.org/10.1016/S0140-9883(01)00078-0

R Core Team (2015). R: A Language and Environment for Statistical Computing. R 
Foundation for Statistical Computing. http://www.R-project.org

Ratti, R., \& Hasan, M. (2013). Oil Price Shocks and Volatility in Australian Stock Returns. Economic Record, 89, 67-83. https://doi.org/10.1111/1475-4932.12034

Sadorsky, P. (1999). Oil Price Shocks and Stock Market Activity. Energy Economics, 21, 449-469. https://doi.org/10.1016/S0140-9883(99)00020-1

Sadorsky, P. (2003). The Macroeconomic Determinants of Technology Stock Price Volatility. Review of Financial Economics, 12, 191-205. https://doi.org/10.1016/S1058-3300(02)00071-X

Sharpe, W. (1963). A Simplified Model for Portfolio Analysis. Management Science, 9, 277-293. https://doi.org/10.1287/mnsc.9.2.277

Tang, K., \& Xiong, W. (2012). Index Investment and the Financialization of Commodities. Financial Analysts Journal, 68, 54-74. https://doi.org/10.2469/faj.v68.n6.5

Tansuchat, R., Chang, C., \& McAleer, M. (2010). Conditional Correlations and Volatility Spillovers between Crude Oil and Stock Index Returns. https://doi.org/10.2139/ssrn.1534043

Wang, X., Smith, K., \& Hyndman, R. (2006). Characteristic-Based Clustering for Time Series Data. Data Mining and Knowledge Discovery, 13, 335-364.

https://doi.org/10.1007/s10618-005-0039-x

Yazdan, G. F., Ehsan, A. G., \& Hossein, S. M. (2012). Is Cointegration between Oil Price and Economic Growth? Case Study Iran. Procedia Social and Behavioral Sciences, 62, 1215-1219. https://doi.org/10.1016/j.sbspro.2012.09.207 